\title{
A INFORMAÇÃO ENFURECIDA E A MISSÃO DO BIBLIOTECÁRIO EM TEMPOS DE PÓS-VERDADE: uma releitura com base em Ortega y Gasset
}

\author{
Elisa Cristina Delfini Corrêa \\ Docente do Departamento de \\ Biblioteconomia e Gestão da \\ Informação e do Programa de Pós- \\ graduação em Gestão da Informação da \\ Universidade do Estado de Santa \\ Catarina. \\ E-mail: elisacorrea61@gmail.com

\section{Marcela Gaspar Custódio \\ Mestranda em Ciência da Informação na Universidade Federal de Santa \\ Catarina. \\ E-mail: marcelagcustodio@gmail.com}

\section{RESUMO}

Artigo que retoma a concepção da missão do bibliotecário, proposta por Ortega Y Gasset na década de 1930, apresentando uma adaptação do que o autor chama de "livro enfurecido" à informação veiculada digitalmente nos dias atuais, em especial diante dos fenômenos da pósverdade. Discute a atualidade dos problemas e a pertinência das soluções indicadas por Ortega y Gasset, analisando a evolução da informação enfurecida nas culturas impressa e digital e traçando um paralelo com as possibilidades de intervenção do bibliotecário a partir de sua missão na sociedade contemporânea.

Palavras chave: Missão do Bibliotecário. Cultura impressa. Cultura Digital. Pós-verdade. Ortega y Gasset.

\section{THE ENRAGED INFORMATION AND THE MISSION OF THE LIBRARIAN IN POST-TRUTH TIMES: a re-reading based on Ortega y Gasset}

\begin{abstract}
This article takes up the conception of the librarian's mission, proposed by Ortega Y Gasset in the 1930s, presenting an adaptation of "enraged book", term used by the author, to the digitally transmitted information in the present day, especially about post-truth phenomena. It discusses the current problems and the pertinence of the solutions indicated by Ortega y Gasset, analyzing the evolution of the information infuriated in the printed and digital cultures and drawing a parallel with the possibilities of intervention of the librarian from his mission in the contemporary society.
\end{abstract}

Key-words: Mission of the librarian. Print Culture. Digital Culture. Post-truth. Ortega y Gasset. 


\section{INTRODUÇÃO}

Para um bom número de pessoas em todo o planeta, o cotidiano contemporâneo está cada vez mais digital: estamos conectados por meio de aparelhos celulares, televisores, computadores e até mesmo pela indireta e discreta influência que recebemos de pessoas também conectadas ao nosso redor que nos repassam informações, opiniões, notícias e atualizações do mundo que recebem pelos meios virtuais. Por fazer parte da vida em sociedade nos dias atuais o uso de aparatos tecnológicos tornou-se objeto de estudos e debates, acadêmicos ou não, em especial por causa da grande influência que exerce sobre nossas formas de interação e conexão com outras pessoas e com o mundo de maneira geral.

Experiências multimídias são vivenciadas com frequência cada vez maior, como nos exemplos a seguir, dentre tantos outros: embalagens de alimentos hoje possuem códigos $Q R$ Code que lidos e traduzidos pelos nossos celulares, instalam aplicativos de jogos; recebemos em aparelhos de smartphone notícias de acontecimentos ao redor do mundo que são notificadas em questão de segundos; realizamos check-in em lojas que proporcionam descontos. São muitos os exemplos e a experiência de vida na era da cultura digital pode ser socialmente rica, uma vez que marcada pelas oportunidades de uma constante interatividade. O cidadão conectado do Século XXI encontra-se em numa grande teia de conversação que articula, dialoga e troca informações incessantemente por meio de softwares e mídias que permitem esta comunicação.

Contudo, o intenso fluxo de informação que circula pela internet apresenta riscos e prováveis prejuízos à sociedade. Diante dessa enorme quantidade de informação que nos chega às mãos de maneira cada vez mais fácil, a linha que separa uma pessoa bem informada de uma desinformada (ou mal informada) torna-se cada vez mais tênue, o que aumenta o alerta contra a alienação diante desse paradoxo da internet.

Esse contexto contribui para o fortalecimento de um fenômeno que, apesar de não ser fruto exclusivo da atual cultura digital, parece ter renascido com força nesse ambiente: a era da pós-verdade, na qual o compartilhamento ininterrupto e indiscriminado de informações pode transformar a internet num ambiente onde 'inverdades' se espalham com muita frequência e mais rapidamente do que os fatos reais.

Essas 'inverdades' vêm ganhando um espaço cada vez maior no ambiente virtual, seja através da veiculação de notícias falsas (fake news), seja por meio das chamadas 'pós- 
verdades' (post-truth). Estas últimas receberam atenção especial no ano de 2016, quando a Oxford Dictionaries a elege como a palavra do ano. 0 dicionário traz como seu significado "circunstâncias em que fatos objetivos são menos influentes na formação de opinião pública do que apelos à emoção ou crenças pessoais" (OXFORD DICTIONARIES, 2017, tradução da autora).

Segundo o Dicionário Priberam, 2017, a palavra 'pós-verdade' dirige-se aos eventos em que a opinião pública e os comportamentos são orientados mais pelos apelos emocionais, falaciosos ou subjetivos, afirmados pelas suas convicções pessoais avulsas, do que em fatos verídicos e atestados.

Para além de ser entendido como um simples e espontâneo fenômeno intrínseco da evolução da Web 2.0 e redes sociais, verifica-se que a propagação de notícias falsas, bem como de interpretações distorcidas em forma de pós-verdade, tem surtido os mais variados efeitos negativos uma vez que pequenos boatos disfarçados de notícias afetam a sociedade em diferentes níveis, desde pessoais - ferindo reputações ou até mesmo levando à linchamentos públicos movidos pelo ódio de pequenos grupos - até de grandes proporções, como o compartilhamento massivo de informações inverídicas sobre política, economia e ciência, desinformando ao invés de informar. Assim, vivencia-se uma época de distribuição de informações confusas, na qual debates em ambiente virtual surgem e multiplicam-se sem a devida citação ou checagem das fontes, além de carregados de opiniões pessoais nem sempre fundamentadas.

As fake news, assim como notícias carregadas de pós-verdades, ocupam diariamente as páginas de mídias sociais como Facebook, por exemplo, influenciando milhares de pessoas ávidas por conteúdos fáceis de digerir que se apresentam de forma colorida e em movimento que são compartilhados compulsivamente sem a devida checagem dos fatos e dos danos que esta ação pode suscitar.

Todo esse contexto aponta a urgente necessidade de desenvolver habilidades para o acesso e uso da informação a fim de distinguir verdadeiras e falsas, bem como adquirir uma maior consciência social em relação à responsabilidade cidadã de replicar informações verídicas advindas de fontes consideradas fidedignas.

Após a eleição da palavra 'pós-verdade' pelo Oxford Dictionaries, percebeu-se uma preocupação crescente em orientar as pessoas para o uso crítico da informação, em especial por parte de profissionais ligados à informação, notadamente os bibliotecários. Nesse sentido, a IFLA (Federação Internacional de Associações de Bibliotecários) 
publicou em sua página oficial um infográfico ${ }^{1}$ contendo recomendações de como identificar notícias falsas, com a justificativa de que esta ação é necessária pois bibliotecários precisam educar e defender o pensamento crítico de seus interagentes.

Outra ação deu-se no dia 31 de Janeiro de 2017, quando a biblioteca pública Gail Borden, em Illinóis, Estados Unidos, promoveu um painel intitulado "Librarians vs. Fake $N_{e w s}{ }^{2 "}$ (Bibliotecários vs. Notícias Falsas) que contou com a presença de uma série de bibliotecários influentes no estado e país para debaterem medidas possíveis para o combate a notícias falsas por bibliotecários e maneiras eficazes de educar interagentes para que saibam distinguir notícias falsas de verdadeiras.

O presente artigo se propõe a uma análise do papel social do bibliotecário diante do quadro informacional contemporâneo, marcado pela 'pós-verdade', retomando e debatendo a Missão do Bibliotecário descrita por José Ortega y Gasset ${ }^{3}$ (2006) em seu discurso de abertura do Congresso Internacional de Bibliotecários realizado em Madri no ano de 1935.

Em sua fala, Ortega Y Gasset aponta como "a nova missão do bibliotecário, incomparavelmente superior a todas as anteriores [...] tornar-se domador do livro enfurecido" (2006, p.39). Seu raciocínio parte do princípio de que a quantidade de livros publicados, assim como a qualidade questionável de muitos conteúdos, somados à "dificuldade do homem comum, a não pensar por sua conta e não repensar o que lê" (p.45) torna-o um objeto de conflito, necessitando de uma atuação proeminente do bibliotecário enquanto domador desse livro enfurecido.

Transpondo a preocupação de Ortega y Gasset para o contexto da sociedade digital, será feita uma análise das formas pelas quais as fontes de informação contemporâneas assumem o mesmo caráter 'enfurecido' diante da semelhante inabilidade das pessoas do Século XXI em se apropriarem consciente e criticamente do que se lê. A análise também busca conferir a atualidade da missão do bibliotecário apontada pelo autor há mais de oito décadas, com enfoque em seu papel de mediador da informação digital.

\footnotetext{
1 https://www.ifla.org/files/assets/hq/topics/info-society/images/how-to-spot-fake-news_440px.jpg

2 https://youtu.be/M6Gvs_KZ9uM

${ }^{3}$ Filósofo espanhol e ministro da Educação da Espanha na época do discurso
} 


\section{A INFORMAÇÃO ENFURECIDA NAS CULTURAS IMPRESSA E DIGITAL}

Durante muitos séculos o suporte em papel dominou a informação registrada e o livro foi - e ainda é - o formato mais conhecido e utilizado para a disseminação de informações e registro de conhecimentos de qualquer natureza. Apesar da existência dos livros preceder a invenção dos tipos móveis de Gutemberg, no Séc. XV, é com esse aparato que se instaura a chamada 'cultura impressa' na qual o livro em papel reinou soberanamente até a chegada dos formatos digitais. A cultura impressa

[...] se constitui no bojo da cultura escrita, sendo uma parte da história desta, relativa, inequivocamente, à invenção da prensa de tipos móveis [...] Antes da prensa, portanto, não havia cultura impressa, havia cultura escrita, isto é, uma cultura manuscrita e fortemente concorrente com a cultura oral. A cultura impressa, então, emerge, se instala, altera as modulações da cultura escrita e cria novos letramentos (RIBEIRO, 2013, p. 13).

Assim, não apenas os livros, mas outros tipos de textos, em especial científicos, passaram a ser publicados e distribuídos em ritmo cada vez mais crescente. Os avanços nas tecnologias de impressão, somados aos avanços no crescimento populacional mundial e ao desenvolvimento da ciência e da tecnologia são, segundo Fonseca (2007, p.25) "ao mesmo tempo causa e efeito da explosão bibliográfica, agora caracterizada menos em termos de livros do que de outros veículos textuais: artigos de periódicos, comunicações a congressos, relatórios de pesquisas, etc".

Fonseca também ressalta que a preocupação de Ortega y Gasset em relação à quantidade de livros e materiais impressos era compartilhada por Paul Otlet e menciona a chamada 'revolução da brochura' durante a década de 1930 que com a publicação dos livros de bolso contribuiu para a explosão bibliográfica.

Paralelamente às facilidades de impressão de grandes tiragens a baixo custo que culminaram em um sem fim de livros publicados, cresceram também as preocupações em relação à qualidade do material impresso. Ortega y Gasset é bastante enfático ao afirmar que a existência e conservação de livros "inúteis ou estúpidos [...] constituem um lastro a mais para a humanidade, que já anda excessivamente curvada sob o peso de outras cargas" (2006, p.43). A esses adjetivos elencados por Ortega Y Gasset, Fonseca adiciona que, em muitos casos, os livros podem ser "perniciosos" e que "quando mal escrito, ele é 
um amigo silencioso que aborrece e pode, mesmo quando bem escrito, desencadear tragédias, como os suicídios dos que leram, em 1774, Die Leiden des jungen Werther, um romance de Goethe" (2007, p.25-26, grifo da autora).

O desenvolvimento científico e tecnológico foi o pano de fundo da invenção de equipamentos de informática em meados do Século XX e os avanços dessa tecnologia colocaram em cena a rede internet marcando a passagem da cultura impressa para a cultura digital. Os textos eletrônicos, primeiramente estáticos, ao longo da segunda metade do século passado e dos primeiros anos do Século XXI, foram tornando-se cada vez mais fluídos e interativos.

O desenvolvimento da internet fez surgir o conceito da web 2.0 que se apresenta como uma evolução da web tradicional, popularmente denominada como web 1.0. Esta pertenceu a 'primeira geração' da internet e perdurou os anos de 1990 a 2003 até que, em 2004 nasce 'segunda geração', sob o nome de web 2.0. Para O’Rilley (2005, p. 2)”, criador do termo, a Web 2.0 pode ser visualizada como: “[...] um conjunto de princípios e práticas que interligam um verdadeiro sistema solar de sites que demonstram alguns ou todos esses princípios e que estão a distâncias variadas do centro".

A orgânica evolução resultante do desenvolvimento e aprimoramento das tecnologias da web transformaram as páginas e tópicos online, basicamente informativos e estáticos, em espaços cada vez mais interativos, hipertextuais, colaborativos e sociais, de acordo com Nesta

[...] antes de 2004 a web era limitada a alguns usuários de classe média americana e européia. Hoje a web é global, barata e baseada no mercado de comunicação de massa, aplicação web para celulares, serviços sem fio e outra dimensão de conveniência: a web não está apenas disponível, ela te acompanha sempre (2010, p. 86).

Ou seja, a internet passa a levar informação para as pessoas, ao invés de levar pessoas à informação (DAVIS, 2005). Como resultado, percebe-se uma "oferta demasiada de informação e poucos filtros efetivos passíveis de reterem os dados essenciais, úteis e do interesse de cada um" (RHEINGOLD, 1993, p. 77).

Assim é que a informação digitalizada potencializou o caráter 'enfurecido' da informação em relação a seus aspectos quantitativos e qualitativos. Desta forma, os problemas em relação à filtragem de informação relevante, bem como o uso crítico da informação, permanecem desafiadores ao bibliotecário ao longo da história da 
humanidade.

Merecem especial atenção os problemas advindos de uma leitura superficial, ausência de criticidade e da urgência no compartilhamento de informações a partir das mídias sociais, proliferando notícias falsas e permitindo um ambiente de extremo relativismo em relação à interpretação dos fatos ocorridos, gerando o fenômeno da pósverdade.

\section{VERDADE, INVERDADE E PÓS-VERDADE: 0 CENÁRIO DA INFORMAÇÃO ENFURECIDA}

O conceito de verdade talvez seja um dos mais controvertidos e relativizados, em especial, nos tempos em que vivemos. A concepção do que é verdadeiro depende de diversas variáveis ligadas a fatores que envolvem os sistemas de valores de cada pessoa, sua experiência e percepção de mundo.

De acordo com Chauí (1995, p. 99) a verdade é admitida, segundo os filósofos modernos, a partir de 07 características: "1. a verdade é conhecida por evidência (a evidência pode ser obtida por intuição, dedução ou indução)"; "2. a verdade se exprime no juízo quando nele a ideia está em conformidade com o ser das coisas ou com os fatos"; “3. o erro, o falso e a mentira se alojam no juízo quando afirmamos de uma coisa algo que não pertence à sua essência ou natureza, ou quando lhe negamos algo que pertence necessariamente à sua essência ou natureza"; "4. as causas do erro e do falso são as opiniões preconcebidas, os hábitos, os enganos da percepção e da memória e os enganos na formulação de juízos sobre as coisas"; “5. em decorrência do cristianismo, para alguns modernos a causa do falso e da mentira também se encontra na vontade, que é mais poderosa do que o intelecto ou o pensamento, e precisa ser controlada por ele"; "6. uma verdade, por referir-se à essência das coisas ou dos outros seres, é sempre universal e necessária e distingue-se da aparência, pois esta produz apenas opinião, a qual é sempre particular, individual, instável e mutável" e "7. o pensamento se submete a uma única autoridade: a dele próprio como capacidade para o conhecimento verdadeiro".

Embora não seja objeto deste artigo a discussão filosófica sobre o conceito de verdade, o breve resumo apresentado por Chauí traz subsídios aplicáveis ao debate sobre os tempos atuais marcados pela informação enfurecida identificada nos fenômenos aqui 
apontados de pós verdade e notícias falsas. Buscar evidências, conformidade com fatos e focar na essência ao invés da aparência trariam indicadores mais seguros para uma análise crítica quanto à veracidade das informações em qualquer época, mas de forma ainda mais potencializada nos tempos digitais.

Encontrar essa verdade demanda um esforço consciente de análise dos fatos, dentre outros métodos, a partir de um trabalho de pesquisa em fontes de informação criteriosamente escolhidas. Não se trata de uma tarefa trivial, pois demanda um conjunto de habilidades específicas para o acesso e uso da informação digital ou não, além de uma consciência crítica e cidadã a respeito de seu papel na sociedade.

Para além da inabilidade de uma grande massa de pessoas em checar os fatos antes de formar sua opinião e compartilhá-la, vivemos dias em que a produção proposital de inverdades tornou-se um negócio lucrativo.

Ryan Holiday em seu livro "Acredite, estou mentindo: história de um manipulador das mídias" explica o fluxo violado de informações midiáticas em ambiente virtual. Segundo o autor pequenos blogs fornecem informações e notícias para blogs "medianos" nos quais jornalistas de meios de comunicação em massa descobrem grandes notícias. 0 autor afirma, a partir de sua própria experiência, que a mídia é manipulada e divulga notícias inverídicas. Para Holiday:

A internet é o que os entusiastas chamam de "tecnologia da experiência", quanto mais usada, mais usuários têm confiança nela. Quanto mais um usuário se envolve com ela, mais à vontade ele se sente e mais acredita no mundo que ela cria. (2012, p. 226)

Segundo o autor existem riscos ao postar histórias sem fundamento, no entanto, são riscos mínimos sem prejuízos; "nos casos raros em que fomos pegos em flagrante, não tivemos que devolver o dinheiro que ganhamos" (op.cit., p.82). Pessoas como Holiday são especialistas em criar e disseminar informação distorcida ou enviesada do tipo "pseudoverdade apoiada em indícios e convicções já que os fatos tornaram-se demasiado complexos." (CASTILHO, 2016, não paginado)

Na chamada 'sociedade da informação', verifica-se em operação um movimento midiático consciente de desinformação que, somado à prática da pós verdade, transforma o mundo da informação em uma perigosa armadilha à qual poucos sabem escapar. 
À medida em que cada um possui sua própria verdade, baseada não em fatos, mas em crenças pessoais geralmente tendenciosas e carregadas de interesses e julgamentos de valor, a ambiguidade vai ocupando espaços cada vez maiores. Assim, um único fato pode assumir centenas de interpretações diferentes e conflitantes. Começam a ser colocados em xeque os conceitos de honestidade e desonestidade, credibilidade e dúvida, verdade e mentira. Vive-se um tempo em que as convicções são mais importantes do que as provas.

A constatação desse cenário apresenta-se como uma oportunidade ímpar para que o bibliotecário exerça sua profissão focado em sua missão de contribuir para a construção de uma sociedade melhor informada e, consequentemente, com melhor qualidade de vida.

\section{A MISSÃO DO BIBLIOTECÁRIO ONTEM E HOJE}

Decorridas quase oito décadas do discurso proferido por Ortega y Gasset, a retomada de sua concepção sobre a missão do bibliotecário pode revelar-se surpreendentemente atual, em especial, porque sua proposta fundamenta-se em seu papel social:

Para determinar a missão do bibliotecário, é preciso partir não do homem que a exerce, de seus gostos, curiosidades ou conveniências, tampouco de um ideal abstrato que pretendesse definir de uma vez por todas o que é uma biblioteca, mas da necessidade social a que serve vossa profissão. E esta necessidade, como tudo que é propriamente humano, não consiste em uma magnitude fixa, mas é, essencialmente variável, migratória, evolutiva; em suma, histórica. (2006, p. 16)

O foco em sua atuação voltada à "necessidade social" tanto confere à missão um caráter mutável, já que a sociedade não é estática e permanece em constante desenvolvimento, quanto confere igualmente um caráter histórico. A historicidade da missão do bibliotecário acompanha, portanto, a história da informação registrada e a evolução de seus suportes, marcada nas últimas décadas pela cultura digital.

Desta forma, a presente análise retoma as ideias apresentadas por Ortega y Gasset em 1935 e, a seguir, faz uma relação com os tempos atuais, traçando um paralelo da missão do bibliotecário na atualidade. 


\subsection{A missão do bibliotecário e o "livro enfurecido” na cultura impressa}

Ortega y Gasset parte do princípio que a palavra 'missão' refere-se àquilo “que um homem deve fazer em sua vida" (2006, p. 3), enfatizando que qualquer missão está intrinsecamente ligada à humanidade, não a objetos por ela criados. Desta forma, desvincula a responsabilidade de cuidar do livro às bibliotecas, indicando claramente que esta pertence ao bibliotecário sendo, portanto, uma missão profissional.

Essa missão, ao longo da história do bibliotecário, sempre enfrentou diversos desafios, mas estes se intensificaram a partir do século XIX quando acontecimentos sociais como a Revolução Francesa que, a partir da análise de Ortega y Gasset, ao destituir a religião como fundamento da sociedade, tornou o livro a última instância de apoio de todo aparato social: "é preciso, pois, agarrar-se a ele como a uma tábua de salvação. 0 livro torna-se socialmente imprescindível" (op.cit., p. 25)

Surge assim o fenômeno da explosão bibliográfica e, com ela, uma avidez por leitura sem precedentes. Com a facilidade da representatividade do livro, o mesmo tornase uma ameaça. Para ele, o instrumento facilitador da informação, volta-se agressivamente contra o homem. De acordo com Carvalho e Reis (2007, p. 36) Ortega y Gasset diz que "o homem chega à conclusão que não é há possibilidade de ler tudo o que precisa e conseqüentemente, as leituras são feitas às pressas, deixando a sensação de impotência e fracasso" e enfatiza que "o livro corre perigo porque se tornou um perigo para o homem" (Ortega y Gasset, 2006, p. 34).

Isto posto, Ortega y Gasset enumera alguns pontos negativos e consequências que a produção acelerada de livros provoca: em primeiro lugar, a dificuldade do homem em lidar com a quantidade de leituras a seu dispor - "já há livros em demasia" (op.cit., p. 40). O número de livros disponíveis é muito maior do que sua capacidade de assimilação e o tempo que possui para a leitura. Como decorrência disso, as pessoas passam a "ler às pressas, a ler mal e, ademais, deixa-o com uma impressão de impotência e fracasso e ao cabo, de ceticismo em relação à sua própria obra" (idem).

Trata-se de uma situação conflitante e sufocante, pois a tarefa do homem de conhecer-se historicamente depende de suas leituras e apenas poderá ser resolvida com a ajuda do bibliotecário e seu esforço de criar "uma nova técnica bibliográfica de um automatismo rigoroso" (op.cit., p.43). Desta forma, em Ortega Y Gasset, a missão do bibliotecário para resolver o primeiro perigo do livro enfurecido parte de uma tarefa 
técnica de organização bibliográfica de forma a reduzir o esforço das pessoas em filtrar a informação necessária e entrega-la de maneira seletiva.

O segundo problema refere-se aos conteúdos: ao mesmo tempo em que "muitos deles são inúteis ou estúpidos" (idem), sentia-se a falta de alguns conteúdos essenciais impedindo o avanço das pesquisas. Neste caso, verifica-se um paradoxo no qual excesso e escassez partem de um mesmo lugar. Para minimizar esse problema, Ortega y Gasset sugere uma ação regulatória por parte do bibliotecário gerenciando o controle da produção de livros de acordo com sua necessidade social. Essa tarefa, segundo o autor, deve ser uma organização feita coletivamente e é tão necessária quanto o controle do trânsito nas grandes cidades. Embora sua fala possa ser interpretada como a sugestão para uma atuação censitória do bibliotecário, é possível entendê-la como uma filtragem de textos relevantes a exemplo do papel de um editor.

0 terceiro ponto refere-se à atuação do "bibliotecário do futuro" que terá que orientar os interagentes leigos, tornando-se o que o autor chama de "médico e higienista" das leituras (2006, p.46). Essa atuação corresponde à missão de mediação entre o livro e seu leitor. É exatamente a partir desse ponto que o autor situa a diferença fundamental entre a missão cumprida pelo bibliotecário até aquele momento e a que deveria vir a seguir: a mudança de concepção da "mera administração da coisa chamada livro" para a concepção da "função vital que é o livro" (idem).

O livro, para Ortega y Gasset, carrega um dizer a ser transmitido e interpretado e, por isso, abriga uma memória que conserva tão somente as palavras. Para que estas reflitam pensamentos, é preciso interpretar as ideias ali contidas e isso não é possível num contexto no qual "se lê muito e se pensa pouco" (op.cit., p. 56).

Ativar o pensamento seria, assim, o papel crucial da mediação do bibliotecário e seu maior desafio diante do "livro enfurecido". Disseminar opiniões com base em informações lidas e não refletidas é um perigo que se multiplica exponencialmente nos dias atuais principalmente por meio da internet e, em especial, das mídias sociais, caracterizando-as como veículos de expressão e disseminação de informações consideradas enfurecidas de acordo com o debate aqui proposto.

Assim, a reflexão levantada por Ortega y Gasset torna-se extremamente necessária nos dias atuais. Repensar a missão do bibliotecário deve ser pauta constante da profissão no contexto da informação digital. É o que se esboça a seguir. 


\subsection{A missão do bibliotecário e a "informação enfurecida" na cultura digital}

O aumento do fluxo e da produção de textos, em especial no formato digital, representa uma sobrecarga de informação à qual Ortega y Gasset sequer poderia imaginar. Se o autor considerava impossível ao leitor acompanhar o crescimento da produção de livros na década de 1930, a condição humana da atualidade diante do fluxo diário de informação pode tornar insuportável a tentativa de cumprir essa tarefa.

Assim é que convivemos com a chamada "ansiedade da informação" (WURMAN, 1991, 2005), provocada pela avalanche de notícias e dados informacionais às quais o cidadão comum é submetido, causando uma situação de estresse que o obriga a encontrar meios de organizar-se para gerenciar esse caos e manter-se saudável e atualizado para permanecer competitivo no mundo do trabalho.

Organizar-se e gerenciar o fluxo de informação significam, em grande medida, aplicar filtros que permitam a recuperação de informação relevante criando tags (etiquetas) a fim de classificá-las de maneira que estejam disponíveis para uso sempre que for preciso. Como visto, nem todas as pessoas possuem habilidades específicas para tal e, assim, muitas perdem-se no emaranhado da informação enfurecida. Nesse aspecto a missão do bibliotecário assume ainda maior relevância social uma vez que seus conhecimentos profissionais lhe permitem navegar pela internet de maneira melhor orientada podendo assim oferecer serviços de informação personalizados. Em outras palavras, parece possível tratar-se ainda de uma solução técnica que tem íntima relação com a missão do bibliotecário nos dias atuais: organizar a informação de acordo com objetivos e públicos específicos.

De certa forma, os catálogos online, portais de periódicos e obras de referência em formato digital representam uma atualização dessas atividades técnicas no meio eletrônico. Por outro lado, em muitos casos não passam de uma simples migração do que já se fazia em papel para a internet nos moldes da web 1.0. Há um enorme potencial colaborativo, hipermidiático e hipertextual ainda a ser explorado.

Para cumprir essa missão, o bibliotecário precisa não apenas migrar suas competências técnicas para o ambiente digital, adaptando seus saberes em uma nova configuração mais adequada ao contexto atual, criando novas propostas de organização da informação digital. É premente reciclar ideias e atitudes, estabelecer diálogos e 
parcerias com outros profissionais que atuam no espaço digital e, em especial, conhecer e ouvir atentamente seu público alvo, acostumado à vida digital. Significa também reconhecer a internet não apenas como ferramenta, mas como campo de trabalho a ser explorado.

O segundo problema apontado por Ortega y Gasset também se verifica na informação que circula digitalmente em potência muito maior do que o que ocorria em 1935: a quantidade e a velocidade com que informações desqualificadas são distribuídas pela internet aumentam a cada segundo.

Hoje é possível afirmar que a informação se enfurece exponencialmente, atravessa países e oceanos em segundos, transportando conteúdos úteis ou "estúpidos" o que caracteriza a realidade informacional atual num ambiente hostil e repleto de pessoas confusas com suas próprias opiniões e argumentos. A informação enfurecida está contemplada em inúmeros compartilhamentos diários em ambientes virtuais, geralmente imunes aos filtros pelos quais deveriam passar.

Essa informação enfurecida - e também muitas vezes disfarçada - usa vestes aparentemente inofensivas e é uma das causas da emergência de uma geração de desnorteada e despreparada para lidar adequadamente com esse contexto informacional, desafiando fortemente o exercício da missão do Bibliotecário nos dias atuais. Realizar esse filtro e facilitar a vida dos interagentes na busca da informação necessária corresponde ao papel de editor sugerido por Ortega y Gasset. Atualmente verifica-se uma crescente inserção do bibliotecário em equipes multidisciplinares responsáveis pela edição de periódicos eletrônicos e em editoras de livros de maneira geral, sejam impressos ou digitais.

Esse quadro aponta a também necessidade da atuação do bibliotecário no que chamamos hoje de curadoria, tarefa na qual responsabiliza-se pela reunião e guarda de informação relevante de acordo com o interesse e necessidades de públicos distintos. 0 processo de curadoria digital garante seleção, avaliação e acesso à produção artística e intelectual através da preservação a longo prazo e envolve procedimentos familiares ao bibliotecário em suas atividades de gestão de estoques informacionais.

Por último, e talvez seja esse o maior desafio para o bibliotecário nos dias atuais, é preciso cumprir sua missão no sentido de orientar para o uso crítico da informação, buscando solucionar o terceiro problema apontado por Ortega y Gasset. 0 melhor caminho para atingir esse objetivo é tornar-se um mediador no desenvolvimento da 
competência em informação em sua comunidade.

De acordo com Belluzzo, Santos e Almeida Júnior (2014, p. 61):

A competência em informação, considerada como um processo que tem por finalidade desenvolver competências e habilidades informacionais para aprimorar o pensamento crítico e analítico das pessoas em relação ao universo informacional, pode ser implementada e desenvolvida em bibliotecas por meio de programas com o apoio de mediadores bibliotecários e professores. Por ser um processo que envolve o desenvolvimento e aprimoramento de atitudes relativas à busca, recuperação, avaliação e disseminação da informação, a mediação da informação é inerente à competência em informação, já que é uma ação de interferência.

Nesse aspecto em especial, são ressaltadas as características de educador que são inerentes à atuação do bibliotecário. Faz parte desse importante papel acompanhar o interagente não apenas na tarefa de encontrar e acessar a informação, mas também na tarefa de compreendê-la e utilizá-la eticamente. Auxiliar sua comunidade a desenvolver habilidades para o uso crítico da informação talvez seja uma das ações mais importantes do bibliotecário nos dias atuais. Em outras palavras, mediar a construção de sua competência em informação, num processo de aprender a aprender:

[...] as pessoas competentes em informação são aquelas que aprenderam a aprender. Elas sabem como aprender, pois sabem como o conhecimento é organizado, como encontrar a informação e como usá-la de modo que outras pessoas aprendam a partir dela. (ALA, 1989, p. 1)

O conceito de aprender a aprender é recorrente entre as definições dos autores na literatura científica. Le Boterf (2003, apud VARELA; BARBOSA; FARIAS, 2016, p. 225), discute esquematicamente competências específicas que devem ser aplicadas nas atividades dos bibliotecários, são elas: "saber agir com pertinência”, sobre competências para agir em situações profissionais; "saber mobilizar saberes e conhecimentos em um contexto profissional", sobre a mobilização de conhecimentos teóricos-práticos; "saber integrar ou combinar saberes múltiplos e heterogêneos"; sobre saber utilizar recursos teóricos e técnicos de seu tempo; "saber transpor", sobre estar apto superar técnicas enraizadas da área; "saber aprender e aprender a aprender", sobre aprendizagem ao longo da vida profissional; "saber envolver-se", sobre o profissional compreender que seus conhecimentos não se encerram nos equipamentos e técnicas. 
Além disso, o papel social que envolve a missão do bibliotecário depende de que ele mesmo seja competente nos processos informacionais e capaz de mediar esse conhecimento de forma contextualizada:

É preciso modular o perfil profissional direcionado para a atuação em uma dada realidade política, econômica, social e cultural, a partir do desenvolvimento de conhecimentos especializados, habilidades e atitudes profissionais que potencializam a emergência de competências gerais e especializadas inerentes à sua área de atuação e seu entorno. (VARELA; BARBOSA; FARIAS, 2016, p. 230).

Isto posto, a missão do bibliotecário nos dias de hoje, disposto de um leque infinito de interagentes com acesso aos mais diversificados conteúdos online deve ser repensada em torno de uma nova configuração de competências direcionadas a esta realidade, caracterizada por um contexto político, econômico, social e cultural específicos da era da pós-verdade e que possam prover às comunidades respostas às suas demandas informacionais.

A competência em informação tem propriedades educacionais e promovem a cidadania, o crescimento pessoal e estimulam a criatividade (JOHNSTON; WEBBER, 2006), pontuações socialmente relevantes para o convívio democrático em ambiente virtual. 0 bibliotecário, atento ao cumprimento dessa missão, torna-se um ator imprescindível para a qualidade de vida na sociedade contemporânea.

\section{CONSIDERAÇÕES FINAIS}

A concepção sobre a informação enfurecida com base nas ideias de Ortega y Gasset mostra-se atual em tempos de comunicação digital em que os fatos assumem lugar secundário na opinião e no comportamento públicos. A missão do bibliotecário, portanto, torna-se vital na era da pós-verdade. Fica ainda mais evidenciado o seu papel social enquanto profissional capaz de criar técnicas especializadas de captura, organização e preservação da informação digital; de suas funções editoriais capazes de filtrar a informação necessária para demandas específicas e, principalmente, de sua atuação enquanto mediador para o desenvolvimento de competências em informação. 
Nesta última, o bibliotecário facilita a formação de cidadãos autônomos para a busca e acesso à informação e, o mais importante, conscientes e críticos para sua utilização visando não somente o proveito próprio, mas também o bem comum.

Ou seja, o compromisso com os interesses de sua comunidade é uma das principais responsabilidades sociais do bibliotecário. Bibliotecários influenciam na maneira como as pessoas consomem o conhecimento e constroem novos saberes, e, por isso, precisam estar munidos de ferramentas úteis contra notícias falsas. Devem, assim, aprender a aprender para, posteriormente, multiplicar esse conhecimento e transformar cada interagente de sua comunidade em um novo multiplicador.

A partir do desenvolvimento destas competências em informação, bibliotecários e interagentes estarão preparados para reconhecer o universo de informações em que estão mergulhados e exigir qualidade em meio à quantidade.

Essa atuação coaduna-se aos pressupostos da $\mathrm{ONU}^{4}$ previstos na Agenda $2030^{5}$ para o Desenvolvimento Sustentável, definida após a conferência das Nações Unidas sobre o desenvolvimento sustentável no Rio+20 em 2012 e adotada por todos os 193 paísesmembros das Nações Unidas em 2015, da qual a IFLA têm participado ativamente.

A Agenda 2030 defende a inclusão do acesso à informação, proteção do patrimônio cultural, alfabetização e alfabetização tecnológica e acesso às tecnologias de informação e comunicação. Tais pressupostos buscam solucionar as questões que envolvem a fúria da informação como debatido neste texto e, portanto, representam uma oportunidade a mais para que o bibliotecário exerça sua missão dentro e fora do ambiente das bibliotecas não mais como o 'domador' sugerido por Ortega y Gasset em 1935, mas como um multiplicador de competências para a formação de um grande número de domadores neste universo de informação ainda enfurecida.

\section{REFERÊNCIAS}

AMERICAN LIBRARY ASSOCIATION. Report of the Presidential Comittee on information literacy: Final report. Disponível em: <http://www.ala.org/acrl/nili/ilit1st.html>. Acesso em: 10 abr. 2017.

BELLUZO, Regina Célia Baptista; SANTOS, Camila Araújo dos; ALMEIDA JÚNIOR, Oswaldo

\footnotetext{
${ }^{4}$ Fundada em 1945, a Organização Mundial das Nações Unidas (ONU) é uma organização mundial formada atualmente por 193 países voluntários em prol da paz e desenvolvimento mundial.

${ }^{5}$ https://nacoesunidas.org/pos2015/agenda2030/
} 
Francisco de. A competência em informação e sua avaliação sob a ótica da mediação da informação: reflexões e aproximações teóricas. Informação e Informação, Londrina, v.19, n.2, p.60-77, ago. 2014. Disponível em:<

https://www.marilia.unesp.br/Home/Graduacao/PETBiblioteconomia/a-competencia-eminformacao..pdf> Acesso em: 10 abr. 2017.

BLACKBURN, Simon. Dicionário Oxford de Filosofia. Rio de Janeiro: Zahar, 1997.

CARVALHO, Kátia de; REIS, Marivaldina Bulcão. Missão do bibliotecário: a visão de José Ortega e Gasset. Revista Brasileira de Biblioteconomia e Documentação, Nova Série, São Paulo, v. 3, n. 2, p. 34-42, jul-dez. 2007.

CASTILHO, Carlos. Apertem os cintos: estamos entrando na era da pós-verdade. Observatório da Imprensa, n. 921, 2016. Disponível em: < http://observatoriodaimprensa.com.br/imprensaem-questao/apertem-os-cintos-estamos-entrando-na-era-da-pos-verdade/> Acesso em: 15 jul. 2017.

CHAUI, Marilena de Souza. Convite a filosofia. São Paulo: Atica, 1995.

DAVIS, I. Talis, Web 2.0 and All That. 2005. Disponível

em:<http://blog.iandavis.com/2005/07/talis-web- 2-0- and-all- that/>. Acesso em: 23 abr. 2017.

FONSECA, Edson Nery da. Introdução à Biblioteconomia. Brasília: Briquet de Lemos, 2007.

HOLIDAY, Ryan. Acredite, Estou Mentindo: Confissões de um manipulador das mídias. São Paulo: Companhia Editora Nacional, 2012.

JOHNSTON, Bill.; WEBBER, Sheila. As we may think: information literacy as a discipline for the information age. Research Strategies, v. 20, n. 3, p. 108-121, 2006. Disponível em: < ftp://ftp.inf.puc-rio.br/pub/docs/FomularioSolicitacoes/Johnston_As-we-may-thinkInformation-literacy-as-a-discipline-for-the-information-age_2005.pdf > Acesso em: 13 abr. 2017.

NESTA, F. Library 2.0 or library III: returning to leadership. Library Management, v.32, n.1/2, 2011. Disponível em: www.emeraldinsight.com/0143- 5124.htm\&gt; Acesso em: 20 mar.

O'RILLEY, Tim. What Is Web 2.0: Design Patterns and Business Models for the Next Generation of Software. 2005. Disponível em:<http://www.oreilly.com/pub/a/web2/archive/what-is- web20.html>. Acesso em: 15 mar.

ONU. Agenda 2030. Disponível em: <https://nacoesunidas.org/pos2015/agenda2030/>. Acesso em: 20 abr. 2017.

ORTEGA Y GASSET, José. Missão do bibliotecário. Brasília: Briquet de Lemos, 2006.

PRIBERAM, Dicionário. Dicionário Priberam. 2017. Disponível em: <https://www.priberam.pt/dlpo/>. Acesso em: 26 jun. 2017.

RHEINGOLD, Howard. The virtual community: homesteading on the electronic frontier. Massachusetts: Addison Wesley, 1993.

RIBEIRO, Ana Elisa. Cultura escrita, cultura impressa e cultura digital: contiguidades e tensões. 
In: FIORENTINI, Leda Maria Rentiaro et. al. (Orgs.) Estilos de aprendizagem, tecnologias e inovações na educação. Brasília, DF: UnB, 2013. Disponível em: <

https://www.academia.edu/17545624/Cultura_escrita_Cultura_impressa_e_Cultura_digital_con tiguidades_e_tens\%C3\%B5es?auto=download> Acesso em: 14 jul. 2017.

VARELA, Aida Varela; BARBOSA, Marilene Lobo Abreu; FARIAS, Maria Giovanna Guedes. Saberes e Competências na formação do bibliotecário: construindo um perfil profissional baseado na interação, sensibilidade e autonomia. In: Competência em informação: políticas públicas, teoria e prátoca. Salvador: UDUFBA, 2016.

WURMAN, Richard Wurman. Ansiedade da informação. São Paulo: Cultura, 1991.

. Ansiedade da informação 2. São Paulo: Cultura, 2005.

Recebido em: 02 de outubro de 2017

Aceito em: 20 de novembro de 2017 